\title{
Percutaneous arterial catheterization for multiple sampling
}

\author{
F. MOR A N, A. R. LORIMER, A N D G. B O Y D \\ From the Cardiopulmonary Unit and the University Department of Medicine, \\ Glasgow Royal Infirmary
}

\begin{abstract}
Two hundred and fifty instances of brachial artery catheterization using a simple percutaneous technique are reported. There have been no serious complications. Where multiple repeated arterial blood sampling is required, this method is superior to others available, particularly when the need for sampling extends over many days.
\end{abstract}

The measurement of arterial blood oxygen and carbon dioxide tensions greatly increases the information available for assessment of cardiopulmonary function for both diagnostic and therapeutic purposes (Bates and Christie, 1964). The measurements are now technically simple (Severinghaus, 1959). Several arterial samples may be required and, if patients in cardiorespiratory failure are being monitored, the need for sampling may extend over several days or weeks. Such samples have been obtained by repeated arterial puncture, by the insertion of a Cournand or a Riley needle, or by a catheterization technique of the Seldinger type (Seldinger, 1953). We report our experience in 250 cases with a newer and simple catheterization technique (Barr, 1961; Amplatz, 1962), which we believe to be superior to all of these methods for repeated and long-term arterial blood sampling.

\section{METHOD}

Only the brachial artery was used. The arm was hyperextended over a sandbag, the vessel was located by palpation, and its position was marked on the skin. Local anaesthetic (procaine hydrochloride $2 \%$ in plain solution) was injected subcutaneously and around the vessel. Normally $1 \mathrm{ml}$. was sufficient and this amount did not obscure arterial pulsation. The catheter assembly ${ }^{1}$ consisted of a 4-in. tapered teflon catheter with Luer-Lok hub closely fitted around a matched needle and stilette. This was inserted in the long axis of the vessel, care being taken to enter the artery in its midline, and was advanced to ensure that the catheter was well inside the lumen. Commonly, the posterior wall of the vessel was pierced. The needle and stilette were partially withdrawn and the teflon catheter was pulled

'Becton, Dickinson \& Co., 'Longdwel' Catheter, Cat. No. 01-0048 back slowly until a pulsatile flow of blood was obtained, whereupon the catheter was threaded up the arterial lumen. The needle was withdrawn completely and the matched teflon obturator was inserted into the catheter, which was then lightly taped to the arm. The obturator occluded the lumen of the catheter and had a screw lock into the hub. There was no interference with arm movement, and normal patient activity was allowed. Samples under sterile conditions were taken as required. With experience it was possible to cannulate the artery and, if necessary, to take the first sample within 10 minutes. On removal of the catheter compression, sufficient to occlude the radial pulse, was applied manually above the insertion site for 10 minutes. The pressure was then released gradually and the site was inspected. If there was no bleeding a light dressing was applied. In a few cases further compression for a variable time was necessary. Paraesthesiae were experienced particularly after infiltration of local anaesthetic and during the period of arterial occlusion following withdrawal of the catheter. While the catheter was in place there was little discomfort and samples could be taken without disturbing the steady state, thus avoiding acute changes in blood-gas tensions.

\section{RESULTS}

Our experience with this technique is summarized in the Table. The catheter was left in place for less

T A B L E

SUMMARY OF EXPERIENCE WITH TEFLON ARTERIAL CATHETERS

\begin{tabular}{l|c|c|c|c|c|c}
\hline \multicolumn{1}{c|}{ Group } & No. & $\begin{array}{c}\text { Average } \\
\text { Duration }\end{array}$ & $\begin{array}{c}\text { Average No. } \\
\text { of Samples }\end{array}$ & \multicolumn{2}{|c|}{ Complications } \\
\hline Short-term & 206 & 3 hours & $\begin{array}{c}5 \cdot 4 \\
\text { I }\end{array}$ & 3 & - & - \\
Long-term & 44 & $\begin{array}{c}7 \text { days } \\
\text { (range 2-15) }\end{array}$ & $\begin{array}{r}9 \\
\text { (range 2-18) }\end{array}$ & 7 & 2 & 5 \\
\hline
\end{tabular}

$\mathbf{H}=$ haematoma, leaking round catheter; $\mathbf{I}=$ inflammation, infection; $\mathbf{P}=$ partial or complete loss of radial pulsation 
than 24 hours in 206 patients, the short-term group. The majority were undergoing our usual cardiopulmonary assessment, which took about three hours to complete, and during this time between five and seven arterial blood samples were analysed. In three patients a significant haematoma occurred and minor bruising was seen in several others, but no serious complication took place. Catheterization was attempted unsuccessfully in a further six.

The long-term group of 44 patients in cardiorespiratory failure had a catheter in place for longer (mean $7 \cdot 1$ days) and had a higher incidence of complications. Minor subcutaneous extravasation of blood occurred in the majority, but in only five was haematoma apparent. On two occasions leakage took place around the catheters. There were two instances of subcutaneous infection without evidence of systemic spread. Both occurred after seven days and each responded quickly to removal of the catheter and the application of a simple dressing. In five patients the radial pulse was weaker in the catheter arm, but within a few days of removal of the catheter the pulse regained its former volume in three of them. Despite diminished radial pulsation there was no evidence of vascular insufficiency in the hand.

\section{DISCUSSION}

Arterial puncture with a hypodermic needle, especially without the use of local anaesthetic, can be painful and is sometimes difficult (Marshall, 1964). It does not lend itself to frequent sampling procedures and cannot be relied upon where accurately timed arterial specimens are required. An indwelling Cournand or Riley needle, although allowing repeated and timed sampling, necessitates immobilization of the arm to prevent displacement of the needle. This hinders normal activity and inconveniences the patient. Catheterization of the artery is therefore preferable. Methods based on the Seldinger technique are widely used, but, although they are appropriate for certain radiological procedures, they require the use of a number of instruments and can be inconvenient to insert single-handed at the bedside or in the clinic. The technique of arterial catheterization reported here has certain advantages where the purpose is repeated arterial sampling. It requires the preparation of a sterile pack containing only a teflon catheter assembly which reduces maintenance to a minimum. The teflon obturator maintains patency of the catheter and obviates the need for flushing with heparinized saline. This mode of catheter insertion is normally a single-handed operation, but when mobile or sclerotic vessels are encountered an assistant can hold them steady by skin traction.

The brachial artery in the antecubital fossa is $\frac{\widehat{\Phi}}{2}$ preferred to the femoral artery for catheterization because it is accessible, it is in a 'clean' area, and क the patient is able to continue with normal activi- $\overrightarrow{0}$ ties with the catheter in situ. In common with $\overrightarrow{\vec{H}}$ others (Berneus, Carlsten, Holmgren, and Sel- $\vec{\omega}$ dinger, 1954; Amplatz, 1962; Tatelman and $\stackrel{2}{\overrightarrow{2}}$ Sheehan, 1962 ; Ikram and Nixon, 1964 ; Baird, $\times$ Lapayowker, Murtagh, and Scott, 1965 ; Cole and N Lumley, 1966), we have found that haematomata occur frequently, but serious complications have of been few and there has been no threat to limb viability. Most reported serious complications have followed femoral rather than brachial artery $\vec{z}$ catheterization or puncture. It seems that the collateral blood supply around the elbow ensures adequate circulation to the hand should the $\mathscr{\odot}$ brachial artery be occluded. Femoral artery. thrombosis is more serious. It frequently endangers the viability of the limb and may require surgical correction. Other reported hazards of femoral puncture include serious occult haemorrhage (Bell, 1962) and even arteriovenous fistula $\stackrel{\mathbb{D}}{\mathscr{D}}$ (Peirce and Ramey, 1953).

Long-term arterial catheterization in the moni- $\frac{9}{3}$ toring of cardiorespiratory failure facilitates frequent measurement of blood-gas tensions both for diagnosis and for assessing the response to therapy. Later, as the patient's condition stabilizes, less frequent determinations are necessary, but $\underset{x}{\stackrel{\nu}{\Perp}}$ if sudden deterioration should occur a sampling $\dot{0}$ source is immediately available. These benefits from long-term insertion in ill patients outweigh o the incidence of complications, none of which has been serious. Close observation of the catheter 0 site is, however, necessary and the catheter should be removed at the first sign of a complication.

We agree with Berneus et al. (1954) and Ward and Green (1965) that arterial sampling should of be more widely available clinically and we believe $N$ that the catheterization technique described here $\underset{\omega}{N}$ is the method of choice.

We are indebted to the physicians of the Glasgow Royal Infirmary and of associated hospitals for $\mathscr{D}$ access to patients under their care.

\section{REFERENCES}

Amplatz, K. (1962). Percutaneous arterial catheterization and its application. Amer. J. Roentgenol., 87, 265.

Baird, R. M., Lapayowker, M. S., Murtagh, F., and Scott, M. (1965). $\sigma$ Percutaneous retrograde brachial arteriography - a nonoperative, noncatheter technique. Ibid., 94, 19. 
Barr, P. O. (1961). Percutaneous puncture of the radial artery with a multi-purpose Tefion catheter for indwelling use. Acta physiol. scand., 51, 343.

Bates, D. V., and Christie, R. V. (1964). Respiratory Function in Disease, p. 21. Saunders, Philadelphia and London.

Bell, J. W. (1962). Treatment of post-catheterization arterial injuries. Use of survey plethysmography. Ann. Surg., 155, 591.

Berneus, B., Carlsten, A., Holmgren, A., and Seldinger, S. I. (1954). Percutaneous catheterization of peripheral arteries as a method for blood sampling. Scand. J. clin. Lab. Invest., 6, 217.

Cole, P., and Lumley, J. (1966). Arterial puncture. Brit. med. J., 1, 1277.

Ikram, H., and Nixon, P. G. F. (1964). Is arterial puncture dangerous? Ibid., 2, 1072.
Marshall, B. E. (1964). Method of arterial sampling. Lancet, 2, 40.

Peirce, E. C., and Ramey, W. P. (1953). Renal arteriography: report of a percutaneous method using the femoral artery approach and a disposable catheter. J. Urol. (Baltimore), 69, 578 .

Seldinger, S. I. (1953). Catheter replacement of the needle in percutaneous arteriography. A new technique. Acta radiol.(Stockh.), 39, 368.

Severinghaus, J. W. (1959). Recent developments in blood $\mathrm{O}_{2}$ and $\mathrm{CO}_{2}$ electrodes. In $A$ Symposium on $p H$ and Blood Gas Measurement, ed. R. F. Woolmer, p. 126. Churchill, London.

Tatelman, M., and Sheehan, S. (1962). Total vertebral-basilar arteriography via transbrachial catheterization. Radiology, 78, 919.

Ward, R. J., and Green, H. D. (1965). Arterial puncture as a safe diagnostic aid. Surgery, 57, 672 . 